\title{
NEONATAL TETANUS
}

\section{DR. FAUZIA ZAFAR}

Associate Professor

Department of Pediatric Medicine

Nishtar Medical College \& Hospital, Multan.

\section{DR. HAFIZ ABDUL GHAFFAR}

Postgraduate Registrar

Department of Pediatric Medicine

Nishtar Medical College \& Hospital, Multan.

\section{DR. JAVARIA RASHEED}

Associate Professor

Department of Pediatric Medicine

Nishtar Medical College \& Hospital, Multan.

ABSTRACT... Objective: To determine the prevalence of neonatal tetanus and frequency of factor leading to neonatal tetanus in patients visiting to Nishtar Hospital, Multan and comparing this data with the past since 2002. Duration: January 2009 to December 2011. Study Design: Descriptive study (cross-sectional). Results: In this study 64 patients with neonatal tetanus were observed over a period of 03 years from January 2009 to December 2011. The ages of babies were from 3-28 days. Mean age was $7.89+1.23$ days the total number of cases rose significantly from $0.8 \%$ of total admission in 2002 to $1.71 \%$ in 2011 . The commonest risk factor was delivery of baby conducted at home (100\%). 2nd commonest factor was non immunized mothers, $95 \%$ of mothers were non immunized against tetanus in pregnancy. $5 \%$ were either partially immunized (received one dose of T.T) or showed vaccine failure despite 2 doses of immunization. In $80 \%$ of the cases there were unskilled birth attendants who conducted deliveries. Among tools which were used to cut umbilical cord, blades were $45 \%$ knives were $30 \%$, and scissors were $25 \%$. Ghee application on cord was found to be present in $30 \%$ of the cases. While Surma applied on cord was $40 \%$. As far as sex is concerned, $45 \%$ cases were females and $55 \%$ cases were males. Majority $(70 \%)$ of cases were of normal birth weight $(>2.5 \mathrm{~kg})$ while $30 \%$ cases were of low birth weight $(<2.5 \mathrm{~kg})$. Inability to take feed/lock jaw $(95 \%)$, and fits $(96 \%)$ were the two most common symptoms. Other less common symptoms were fever ( $70 \%$ ) and generalized stiffness ( $85 \%)$. All the patients were born at home by spontaneous vaginal delivery. Conclusions: The number of neonatal tetanus cases are increasing progressively despite the claims of wide coverage of Tetanus Toxoid Vaccination of female population by EPI. In our setup the factors which lead to Neonatal Tetanus are; non immunization of mothers during pregnancy, home delivery, delivery by non skilled birth attendants, application of ghee/surma on umbilical cord and cutting of umbilical cord by unsterilized tools (scissors, kitchen knife, blade). If proper immunization antenatal care and hygienic delivery practices are followed and all these factors are overcome, disease can be controlled and mortality can be reduced.

Key words: Neonate, Tetanus, Factors, Frequency. NNT, (Neonatal tetanus) EPI (Expanded Programme of Immunization).

\section{INTRODUCTION}

Tetanus was first described by Hippocrates, and Areteus about 24 centuries ago ${ }^{1}$. It remained obscured till Carrle and Rattone in 1884, when they tested rabbits with suspension of an acne pustule and observed fatal attacks of the disease ${ }^{2}$. Finally the bacillus was demonstrated by Kitasato in 1889 in human pus culture ${ }^{3}$. This then led to production of tetanus antitoxin which was then commercially used in World War I. Tetanus is an acute spastic paralytic illness caused by tetanospasmin; a powerful neurotoxin produced by clostridium tetani. If it occurs in neonatal period then it is called neonatal tetanus ${ }^{4}$. It is an Expanded Program of Immunization (E.P.I) related infectious disease associated with high mortality and morbidity. It constitutes a significant number of hospital admissions in some developing countries ${ }^{5}$. The expanded programme on Immunization
(EPI) in Pakistan annually targets around 5.8 million children aged below 1 year to protect against 8 vaccinepreventable diseases and 5.9 million pregnant women to protect them and their newborns from tetanus through routine immunization services ${ }^{5,6}$.

For a long time Neonatal tetanus was regarded as the dominant cause of neonatal mortality in Pakistan accounting for $70 \%$ of all Neonatal deaths ${ }^{7}$. Baseline survey conducted prior to the introduction of EPI in 1978 indicated that the incidence of neonatal tetanus was 11 per 1000 population under 15 years of age and the case fatality was $100 \%$.

There are estimates that almost 28,000 cases of neonatal tetanus occur in Pakistan annually with almost 22,000 deaths $^{8}$. 
Maternal and Neonatal tetanus coverage rates vary with a national wide coverage of $41.3 \%$ for mothers with children $<1$ year of age ${ }^{9}$.

Case fatality in community settings is very high, however upto $78 \%$ survival is reported in tertiary care settings with intensive care and respiratory support ${ }^{10}$.

Billoo et al reported reduction in the mortality of neonatal tetanus from 50-24\% at the Civil Hospital Karachi' .

The Government has committed to achieving the 4the MDG, which aims for a $2 / 3$ reduction of under 5 mortality between 1990-2015, yet infant and child mortality rates remain high. Most recent UNICEF statistics for Pakistan show a child mortality rate of 101 and IMR of $80 / 100,000$ from 130 and 100 respectively, since 1907.

It remains an important public health problem in developing countries, where Maternal and Neonatal Tetanus kills one baby every nine minutes. In many of these countries, it is one of the avoidable cause of death in neonatal period. It has been practically eliminated from developed countries.

The risk factors of neonatal tetanus are related to prenatal, natal and postnatal, factors including lack of proper antenatal care, lack of maternal immunization with tetanus toxoid (T.T), unhygienic delivery and improper cord care ${ }^{12}$.

The portal of entry is usually umbilical cord and incubation period is taken from time of birth. Studies have shown that exposure at the time of delivery or within first 3 days of life to substances contaminated with tetanus spores carries significant risk of developing tetanus ${ }^{13}$. The shorter the incubation period, the worse the prognosis ${ }^{3}$.

Initial symptoms may be very subtle and may pass unnoticed by mother e.g. fever, poor sucking and irritability but only later will the baby present with frank spasms or convulsions. The diagnosis is mainly clinical. Laboratory data is non-specific and non-supportive ${ }^{14}$.
The classical scenario is a home delivered baby, born to an unimmunized mother, cord cut with unsterilized instrument, remains well for first few days of life then develops reluctance to feed, stiffness and fits ${ }^{15}$. If not taken to a tertiary care center, the disease is invariably fatal.

The natural history is that the toxins which are adherent to receptors are degraded or become inactive in 3-4 weeks and if patient is kept alive and managed well. The outcome is good and recovers mostly without sequelae ${ }^{16}$.

In Pakistan an overall incidence was $1 / 1000$ during the year 1998. In Sindh alone, 916 cases were reported during 1997, incidence being less than 1/1000 live births ${ }^{17}$. In Dadu district of Pakistan, number of NNT cases reduced from 53 to 14 in 10 years $(1994-2003)^{18}$. It is evident from the results of a study in Bhakkar district Pakistan that knowledge of Traditional Birth Attendants is very deficient regarding prophylaxis of neonatal tetanus ${ }^{19}$. The neonatal mortality rate due to tetanus in Lora Lai district Pakistan was $23 / 1000$ live births in $2001^{20}$. Among 797 NNT cases reported from EMR in 2005, 518 (65\%) occurred in Pakistan. NNT contributes to high infant mortality in Balochistan $(130 / 1,000)^{21}$.

\section{OBJECTIVE}

To determine the prevalence of neonatal tetanus and frequency of factors leading to neonatal tetanus in the newborns admitted in the neonatal unit of Nishtar Hospital Multan and comparing this data with the past i.e. 2002 onwards.

\section{MATERIALAND METHODS}

\section{Setting}

Paediatric department Nishtar Hospital, Multan.

\section{Duration}

January 2009 to December 2011.

\section{Study design}

Descriptive study (cross-sectional). 


\section{Inclusion Criteria}

Age; neonate of age 3-28 days of life.

Gender; both male and female.

Any patient presenting with normal ability to suck and cry during first 2 days of life but between 3-28 days of age, could not suck normally, became stiff, had Trismus (inability to open mouth), provoked / unprovoked seizures and fever, were selected as NNT cases.

\section{Exclusion Criteria}

Patients with neonatal sepsis.

Patients with neonatal meningitis.

Patients with metabolic fits.

\section{Data collection procedure}

64 diagnosed cases of NNT fulfilling the inclusion and exclusion criteria were included in the study. Permission was taken from ethical committee before starting study. Written informed consent was taken from the attendants of all patients.

History from mother was taken regarding immunization (2 doses of tetanus toxoid during pregnancy), their vaccination cards were checked. H/O delivery, at home or hospital, $\mathrm{H} / \mathrm{O}$ type of tool which was used for cutting cord whether it was knife, scissor, or blade, $\mathrm{H} / \mathrm{O}$ application of Ghee on cord after cutting, and if delivery conducted by non skilled birth attendant or by professional trained birth attendant.

Clinical examination of neonate was performed. If there were symptom of inability to suck and cry and inability to take feed after first 2 days of healthy and normal life. Signs of inability to open mouth, stiffness, fever $(>1000$ F), provoked and unprovoked seizures usually sensitive to touch, light and sounds were present, a clinical diagnosis of NNT was made, and these patients were included in the study. Patients with sepsis were excluded by their negative blood, urine and CSF, culture reports. Neonatal meningitis was excluded by CSF complete examination and culture reports. Metabolic fits were ruled out on basis of normal blood sugar, serum calcium and electrolyte levels. of the past 10 years i.e. from 2002 onwards.

\section{Data analysis}

All the information collected were entered into SPSS version 10.0 and were analyzed through its statistical package. The quantitative variable like age was presented by calculating mean and standard deviation. The qualitative variables like gender, immunization, tool sterility, material applied to cord, delivery conducted by unskilled birth attendant and home delivery etc. were presented by calculating frequency and percentage.

\section{RESULTS}

In this study 64 patients with neonatal tetanus were observed in three years duration.

The ages of babies were from 3-28 days mean age was $7.89+1.23$ days. Fig. 4

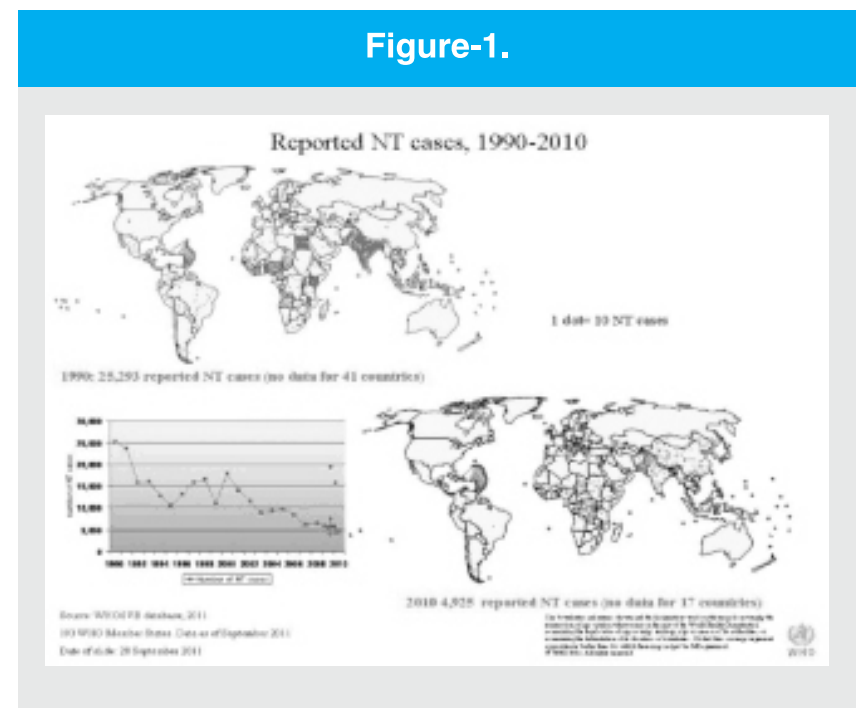

The number NNT patients increased from $0.8 \%$ of total admission in 2002 to $1.71 \%$ in 2011 . Figure-3 \& Table-I

On history taking from mother, the commonest factor was delivery of baby conducted at home (100\%). Then the other 2nd commonest factor was non immunized mothers, $95 \%$ of mothers were non immunized against tetanus in pregnancy. $5 \%$ were either partially immunized (received one dose of T.T) or showed vaccine failure despite 2 doses of immunization.

The data of NNT prevalence was compared with the data 

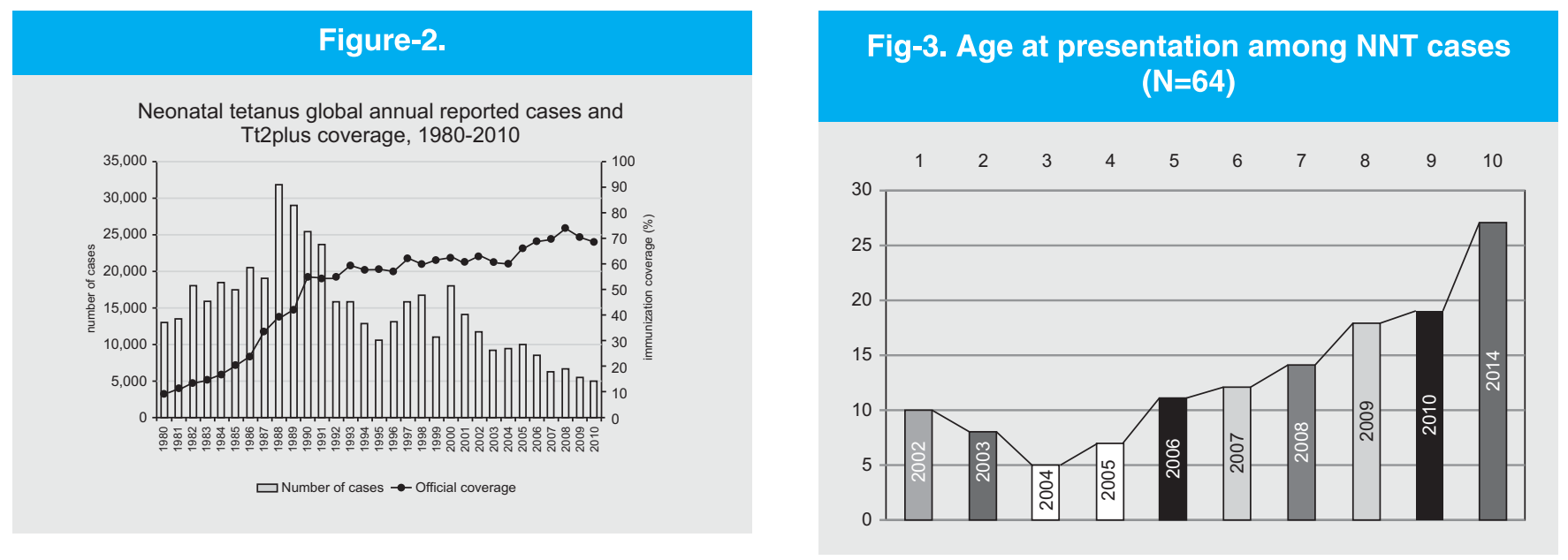

\begin{tabular}{|c|c|c|c|}
\hline Year & $\begin{array}{l}\text { Total no. of } \\
\text { cases }\end{array}$ & Cases of NNT & $\begin{array}{l}\% \text { of total } \\
\text { admission }\end{array}$ \\
\hline 2002 & 1256 & 10 & $0.8 \%$ \\
\hline 2003 & 1206 & 8 & $0.66 \%$ \\
\hline 2004 & 1342 & 5 & $0.67 \%$ \\
\hline 2005 & 1132 & 7 & $0.56 \%$ \\
\hline 2006 & 1308 & 11 & $0.84 \%$ \\
\hline 2007 & 1324 & 11 & $0.9 \%$ \\
\hline 2008 & 1456 & 14 & $0.96 \%$ \\
\hline 2009 & 1485 & 18 & $1.21 \%$ \\
\hline 2010 & 1548 & 19 & $1.22 \%$ \\
\hline 2011 & 1573 & 27 & $1.71 \%$ \\
\hline
\end{tabular}

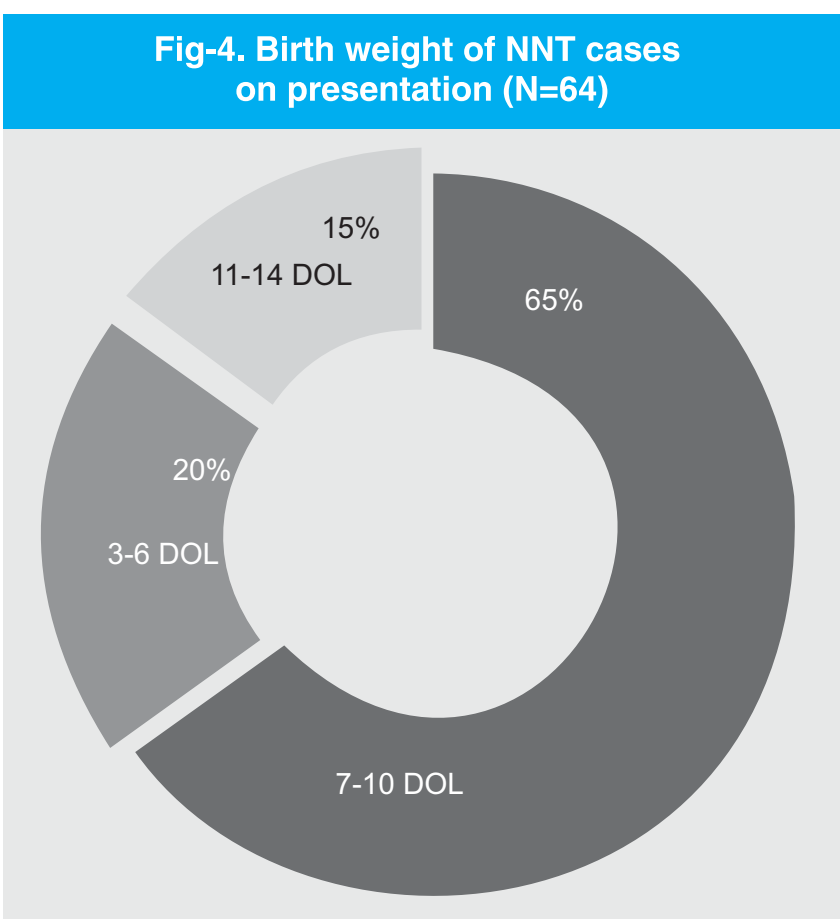

In $80 \%$ of the cases there were unskilled birth attendants who conducted deliveries.

Among tools which were used to cut umbilical cord, blades were $45 \%$ knives were $30 \%$, and scissors were $25 \%$.

Ghee application on cord was found to be present in $30 \%$ of the cases. While Surma applied on cord was $40 \%$. And in $30 \%$ of patients, none was applied on umbilical cord.

As far as sex is concerned, $45 \%$ cases were females and $55 \%$ cases were males.

Majority $(70 \%)$ of cases were of normal birth weight $(>2.5 \mathrm{~kg}$ ) while $30 \%$ cases were of low birth weight $(<2.5 \mathrm{~kg})$. Figure-5

Inability to take feed/lock jaw (95\%), and fits (96\%) were the two most common symptoms. Other less common symptoms were fever $(70 \%)$ and generalized stiffness (85\%). 


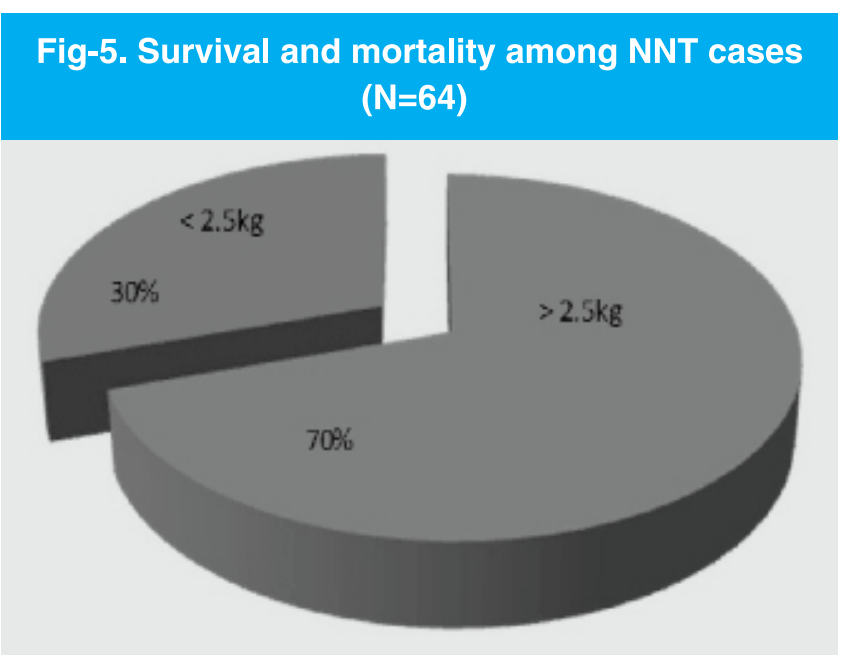

All the patients were born at home by spontaneous vaginal delivery and were delivered at full term. $65 \%$ cases presented at $7-10$ days of life. $20 \%$ presented at 36 days of life. And $15 \%$ cases were presented at 11-14 days of life. Figure-4

Major complications which were observed in these cases were aspiration of feeds causing aspiration pneumonia $(30 \%)$, laryngospasm leading to apnea $(10 \%)$, ventilation induced pneumothorax (3\%), and arrythmias (7\%). Out of 64 cases, $30 \%$ patients died and $70 \%$ survived. Figure-6

\section{DISCUSSION}

The Government of Pakistan aims to control neonatal tetanus through a number of mechanisms: provision of TT-2 to all pregnant women through the EPI, supplementary immunization activities for all women of child bearing age in districts of the country where neonatal tetanus deaths are reported, and provision of thorough antenatal care as detailed in the Reproductive Health Services Package. The policies however may be inconsistent as the EPI expects the Lady Health Workers to provide tetanus toxoid, whereas the Reproductive Health Services Package holds Lady Health Workers responsible only for motivating and referring women for immunization. As has been noted, rates of tetanus toxoid coverage remain low and have actually fallen over the last few years. More alarming still is evidence from selected surveys that coverage may be even lower than reported by EPI figures ${ }^{4}$. Fig. $1 \& 2$

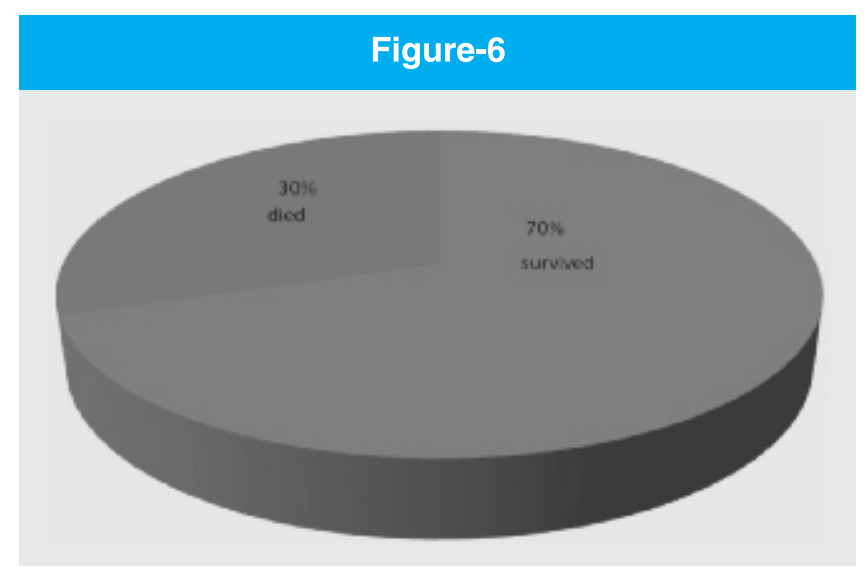

Death rate from NNT has been used as an indicator of health and risk status of mothers and children, and evaluation of primary health care services in a given community. NNT incidence in world is variable reflecting the status of health care facilities. Unfortunately Pakistan still lies in the list of countries where NNT is still one of the infectious diseases among neonates contributing to mortality.

According to a study in India in 2006, mortality rate was $66.3 \%$ and there is a persisting lack of antenatal care, and deliveries are still conducted by untrained persons ${ }^{22}$. $63.6 \%$ mortality rate among NNT cases was found in Nigeria in 15 year experience and one of the determinants was non immunization of mother against tetanus ${ }^{23}$.

In a case control study of risk factors for NNT in Karachi Pakistan, attributable risk percent for cord application was $69 \%$ and for home delivery was $31 \%$ and for use of kitchen knife was $15.2 \%{ }^{24}$.

Our study did not intend to look at the exact incidence or prevalence of the disease in the community because it is a single center study. However it does point towards the magnitude of the problem. All these included cases were born at home $(100 \%)$. Neither was born at any clinic or hospital setting. A hospital based study in Nigeria showed that $73.3 \%$ cases of NNT were delivered at home ${ }^{25}$. According to a study in LORA LAl district Pakistan, majority (96\%) of the cases were delivered at home $^{26}$. 
In our study, $40 \%$ of patients belonged to district Dera Ghazi Khan, 20\% belonged to district Muzaffar Garh, $15 \%$ were from district Multan, 10\% from district Barkhan, $8 \%$ were from district Khanewal and 7\% from Kolhu Balochistan.

95\% patients in the study had their mothers non vaccinated against tetanus during their pregnancy. They did not receive 2 doses of tetanus toxoid in their 7 th and 8th month of gestation. $2 \%$ were fully immunized and showed ineffectivity of vaccine. $3 \%$ among them were partially immunized i.e. received only one dose of T.T in pregnancy.

Only about $52 \%$ of postpartum women of child bearing age showed serological evidence of adequate immunization against tetanus, as reported by EPI $2010^{4}$.

Non skilled birth attendants or any elderly untrained family member at home conducted deliveries in $80 \%$ of the cases. While $20 \%$ of the babies were delivered by nurses, DAl's or by LHV. According to a study in Nigeria, only $35 \%$ of pregnant women were attended by skilled personnel at delivery ${ }^{27}$.

In our study, $30 \%$ of the cases, substance applied on the cord was Ghee. And in 40\% cases surma was applied on umbilical cord after cutting. In a study held in Karachi Pakistan in 2004, out of 125 NNT cases, ghee and surma were applied in 106 cases. While Bennette et al in Northern areas observed most commonly applied substance at delivery or in post delivery period was oil $(56 \%)$, ghee (19\%), surma $(5 \%)$, cow dung $(2 \%)^{28}$.

Main tools which were observed to be used in the study were shaving blade $(45 \%)$, knife $(30 \%)$, and scissors (25\%). In the same study of Karachi mentioned above for ghee application on cord, it was observed that blade usage was in 20 out of 125 cases, kitchen knife was used in 19 and scissor was used in 40 cases $^{24}$.

A study on neonatal tetanus in Africa showed evidences that Tetanus was found to be mainly from social and environmental factors, such as poor hygiene, most importantly use of non-sterile materials in treating the stump of umbilical cords in newborns ${ }^{29}$. Zullfiqar Bhutta published an article in PRB in 2003 and emphasized antiseptic cord cutting and care practices in newborns to keep them prevented from $\mathrm{NNT}^{30}$.

In this study, $55 \%$ cases were males and $45 \%$ cases were females. This slight increase might be due to relatively better hospital care providing to male child as compared to females who are mostly neglected in our social set up. Reports gathered from both hospital and community based surveys showed that the ratio of male to female neonatal tetanus cases world wide is $1: 1^{31}$.

As far as birth weight was concerned, which is a significant predictor of mortality, Majority $(70 \%)$ of cases were of normal birth weight $(>2.5 \mathrm{~kg})$ while $30 \%$ cases were of low birth weight $(<2.5 \mathrm{~kg})$. however mortality was higher in low birth weight babies. $66 \%$ expired patients were of low birth weight. Low birth weight is associated with relatively poor outcome in NNT. Dikici published his study in 2008 showing that deceased NNT cases were having low birth weight $<3 \mathrm{~kg}$ as compared to survived cases $^{32}$.

When incubation period was studied among cases, majority i.e. $65 \%$ cases presented at 7-10 days of life. $20 \%$ presented at 3-6 days of life. And 15\% cases presented at 11-14 days of life. A short incubation period has been associated with significant mortality previously as well as in this study especially less than 7 days. $56.6 \%$ expired patients were of age $<7$ days of life. The proposed reasons are increased virulence of infectious agents and/or decreased host resistance.

A study by Richard looked into the outcome and prevalence of neonatal tetanus in Nigeria which was published in 2011. In his study $30 \%$ of the patients presented between 3-7 days of life while $20 \%$ of the patients presented between 8-12 days of life ${ }^{33}$.

Neonatal tetanus has some varied presenting symptoms. The two most common symptoms observed were lock jaw $95 \%$ and fits $96 \%$. Other less common symptoms were fever (70\%) and generalized stiffness (85\%). Bala Hassan did a survey on neonatal tetanus in a district hospital in North East Nigeria, where he found the most common presenting symptoms inability of sucking, 
stiffness, fits and fever from 2006-2009 ${ }^{34}$.

$30 \%$ patients died in this study and $70 \%$ survived. Survival rate has improved however, than before. Among these $30 \%$ expired patients, those who presented before 7 days of life were $(56.6 \%)$. Out of these $(66.6 \%)$ were of low birth weight $<2.5 \mathrm{~kg}$. And $(33.3 \%)$ were of normal birth weight. Fig. 6

The reported mortality in one study in Pakistan due to tetanus in 1977 was $50 \%$ while in 1989 , it decreased to $24 \%{ }^{35}$. Neonatal tetanus mortality rate was $23 / 1000$ live births in 2003-2004 according to a study performed in Lora Lai district Pakistan ${ }^{38}$.

According to WHO study, NNT cases reported in Pakistan in 2003 were 812 and in 2009, were 781. A recent study from a tertiary care hospital in Lahore reported $100 \%$ mortality among premature and $44.4 \%$ among full term neonates with tetanus ${ }^{36}$.

Major complications which were observed in this study were aspiration of feeds causing aspiration pneumonia $(30 \%)$, laryngospasm leading to apnea $(10 \%)$, ventilation induced pneumothorax (3\%), and arrythmias (7\%). Poudel did a study in Nepal in 2008 on neonatal tetanus and found aspiration pneumonia, tachycardia, uncontrolled seizures, apnea, ventilation induced pneumothorax, rhabdomyolysis and persistent fever ${ }^{37}$. As the most common cause of mortality.

\section{CONCLUSIONS}

Approximately 22,000 newborns die each year in Pakistan from easily preventable tetanus infections. Neonatal tetanus is largely attributable to three risk factors: lack of maternal immunization with tetanus toxoid, unhygienic delivery and unhygienic umbilical cord care during the first week of life.

In Pakistan, unhygienic cord care includes use of a dirty razor blade or knife to cut the umbilical cord during birth and practices such as applying ghee (clarified butter) to the raw stump of the umbilical cord. Ensuring that every pregnant women receives two shots of tetanus toxoid during pregnancy, or that all women of childbearing age receive three shots over a two year period can prevent the deaths of both newborns and their mothers.

The Government of Pakistan is failing in its duty to help its younger citizen survive. Pakistan will fail to meet 4th MDG because an annual progress rate of $1.6 \%$ is not sufficient and at least $8.4 \%$ decrease is needed to succeed.

\section{Copyright@ 02April, 2012.}

\section{REFERENCES}

1. Chen C, Fu Z, Kim J, Joseph T. Gangliosides as High Affinity Receptors for Tetanus Neurotoxin. JBC 2009;284(39):26569-77.

2. Carrle and Rattone. Studio experimentale Sul, Eziologia del tetano. GAcad Med. 1984;32:74-180.

3. How stuff works. Kitasato Shibasaburo. [Online]. 2008 [January 2012]; Available from:URL:http://science.how stuffworks.com/dictionary/famous-scientists/biologists/ kitasato-shibasaburo-info.htm.

4. Arnon SS. Tetanus. In: Kleigman RM, Behrman RE, Jenson HB, Stanton BF, editors. Nelson text book of pediatrics. Philadelphia: Elsevier; 2008: p.1228-30.

5. WHO, UNICEF, UNFPA. Maternal and Neonatal Tetanus Elimination by 2005, Strategies for achieving and maintaining elimination. Nov2000.

6. Hassan, A.H Bosan, K.M. Bile WHO, A review of EPI progress towards achieving coverage targets: present situation and way forward Eastern Mediterranean health journal, vol.16: supplement 2010.

7. Galazka A, Gasse F, Henderson RH, Neonatal tetanus and the global expanded programme on immunization. In:Kessel E, Awan A.

8. Ali N. Maternal and neonatal tetanus in Pakistan. In: Programme and abstracts of the Neonatal Paediatric Congress. 2011 April; Pakistan Paediatric Association, Bhurban, Pakistan.

9. Oxford policy Management. Social Action Programme SAPP II midterm review. Performance Indicators 19911999. Islamabad, Pakistan, 2000.

10. Hassan M, Raza SH. Neonatal tetanus in Pakistan. J Pak Inst Med Sci 1988; 4 (1-2): 198;201.

11. Billoo AG, Ali SMI. Management of neonatal tetanus- 
role of mothers in increasing survival. Specialist 1992; 8:93-100.

12. Begum S, Begum I. Analysis of Maternal mortality in a Tertiary care hospital to determine causes and preventable factors. JAyub Med. 2003;15(2).

13. Afshar M, Raju M, Ansell D, Thomos P. Narrative Review: Tetanus - A Health Threat after Natural Disasters in Developing Countries. Ann Internal Med. 2011;154(5):329-35.

14. Ryan T, Cynthia G. Tetanus. CDC. 2011.

15. Dire DJ, Kulkarni R. Tetanus in Emergency Medicine. Medscape 2011.

16. Mwaniki M, Methenge A, Gwer S. Neonatal Seizures in a rural Kenyan District Hospital: Aetiology, Incidence and outcome of hospitalization. BMC Med. 2010;16(8).

17. Module for case investigation and disease surveillance Sindh. May 1998.

18. Lambo JA, Memon MI, Khahro ZH. Epidemiology of neonatal tetanus in rural Pakistan. JPMA. 2011;61:1099.

19. Ismail K, Sarmad R, Akram M. Assessment of Knowledge About Prophylaxis Of Neonatal Tetanus Among Traditional Birth Attendants. Biomedica. 2007;23.

20. Quddus A, Lubyb S, Pervaiz Y. Neonatal tetanus: mortality rate and risk factors in Loralai District, Pakistan. Internal J epidem. 2001;31(3):648-53.

21. WHO. Disease early warning system and response in Pakistan. Weekly Epidemiological Bulletin. 2011;19(2).

22. Basu S, Paul DK, Ganguly S, Chandra PK. Risk factors for mortality from neonatal tetanus: 7 years experience in north bengal, India. Ann Trop Paediatr. 2006;26(3):233-9.

23. Fetuga BM, Ogunlesi TA, Adekanmbi FA. Risk factors for mortality in neonatal tetanus: a 15-year experience in sagamu, Nigeria. World J Pediatr. 2010;6(1):71-5.

24. Raza SA, Akhtar S, Avan BI, Hamza H, Rahbar MH. A matched case-control study of risk factors for neonatal tetanus in Karachi, Pakistan. J Posgrad Med. 2004;50(4):247-51.

25. Davies-Adetugbo AA, Torimiro SE. Prognostic factors in neonatal tetanus. Trop Med Int Health. 1998;3(1):9-13.

26. Quddus A, Lubyb S, Pervaiz Y. Neonatal tetanus: mortality rate and risk factors in Loralai District, Pakistan. Internal J epidem. 2001;31(3):648-53.

27. Oruamabo RS. Neonatal tetanus in Nigeria; does it still pose a major threat to neonatal survival? Arch Dis Child. 2007;92(1):9-10.

28. Bennett J. Protective effects of Topical antimicrobial against Neonatal tetanus. Intern J Epidemiol. 1997;26(4):897-903.

29. Emeribe VC, Akah LU. Neonatal Tetanus in African Children: Causes, Symptoms, Predisposing Factors, Prevention and Control. Arts and Social Sciences J. 2011;23.

30. Bhutta ZA, Darmstadt GL. Using Evidence to Save Newborn Lives. [Online]. 2003 [January 2012]; Available from: URL: http://www.prb.org/Publications/Policy Briefs/UsingEvidencetoSaveNe wbornLives.aspx.

31. Silvers MJ, Haddy R. A method for adjusting gender bias in neonatal tetanus reports in Egypt 1991. Epidemiol Infect. 2002;128:169-74.

32. Dikici B, Uzun H, Yilmaz KE, Tas T, Gunes A. Neonatal tetanus in Turkey; what has changed in the last decade? BMC Infect Dis. 2008;8:112.

33. Onalo R. Prevalence and outcome of neonatal tetanus in Zaria, Northwestern Nigeria. J Infect Dev Ctries. 2001;5(4)255-59.

34. Hassan B. Popoola A. A Survey of neonatal tetanus at a District General Hospital in north-east Nigeria. Trop Doct. 2011;41(1):18-20.

35. Billoo AG, Inkisar SM. Management of neonatal tetanus role of mothers in increasing survival rates. Specialist. 1992;8(2):93-99.

36. Shah AA, Ali AS, Hussain RR, Hussain A, Saeed A, Butt TK. Complications and outcome of neonatal tetanus. PakPaed J. 2007;31(3):126-31.

37. Poudel P, Budhathoki S, Manandhar S. Tetanus. Kathmandu Uni Med J. 2009; 7(3):315-22.

38. Griffiths UK, Wolfson LJ, Quddus A. Incremental costeffectiveness of supplementary immunization activities to prevent neonatal tetanus in Pakistan. Bulletin of the World Health Org. 2004;82:643-51. 
Correspondence Address:

Dr. Fauzai Zafar

Associate Professor

Pediatric Medicine Unit-I

Nishtar Medical College \& Hospital, Multan

fauziawaqar@yahoo.com
Article Citation:

Zafar F, Rasheed J, Ghaffar HA. Neonatal tetanus.

Professional Med J Dec 2012;19(6): 773-781.

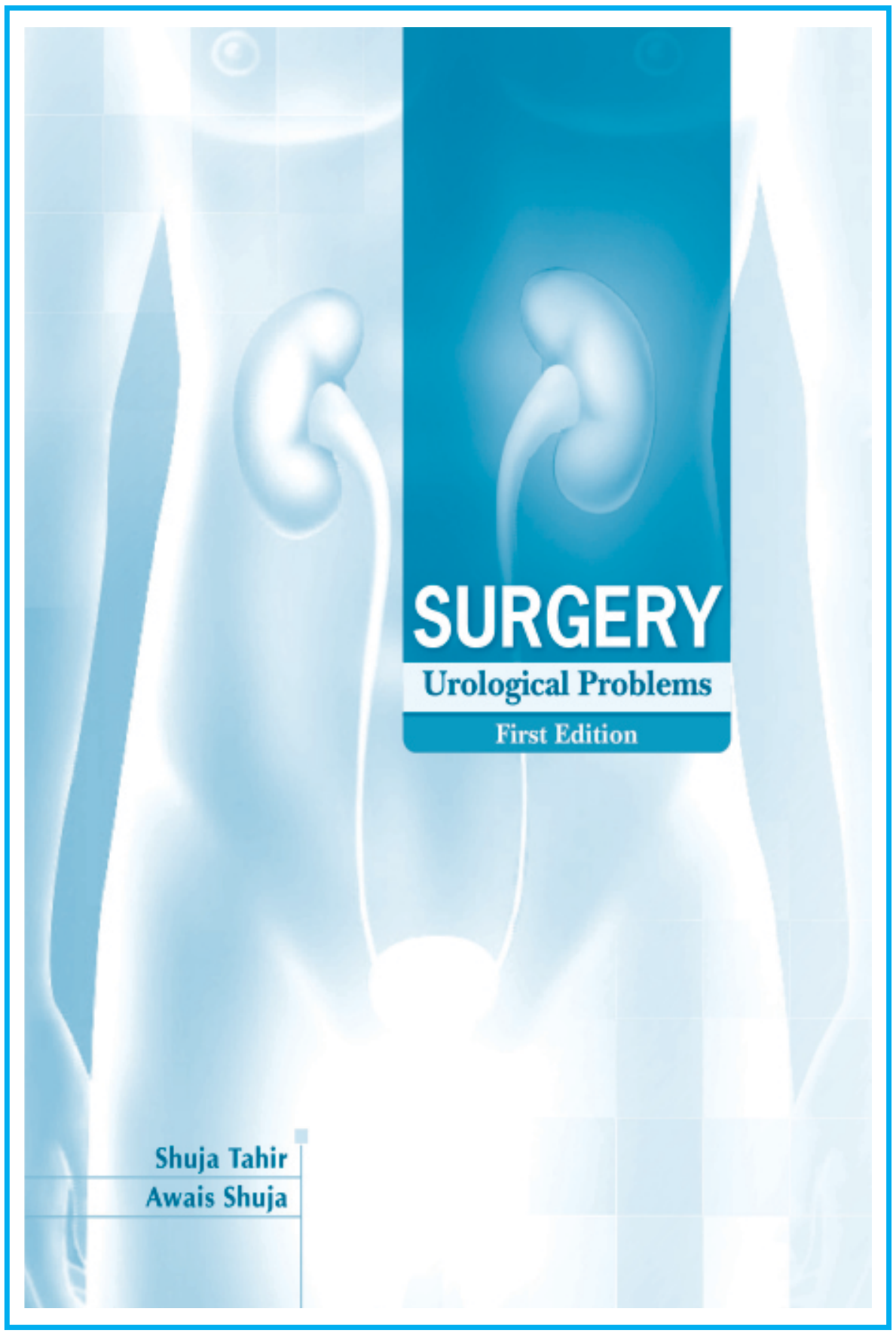

